\title{
Student's Perception of English Learning by Using Rap Music Media
}

\author{
Sri Lestari ${ }^{1 *}$ \\ ${ }^{1}$ Department of English Education, Universitas Muhammadiyah Surabaya, Surabaya, Indonesia \\ *Corresponding author. Email: sri.lestari@fkip.um-surabaya.ac.id
}

\begin{abstract}
Rap music has a decisive role in teaching to help students feel happy and relaxed. There are various obstacles found in using it, such as cultural constraints and the fast tempo to pronounce its lyrics. This study aimed to analyse the perceptions of students who perceived English learning by using rap music media. The population was 36 elementary school students, while the sample was 18 students at English extracurricular classes in private elementary schools in Depok, West Java. They had received English language teaching by using rap music media from September 2017 to December 2017. The research data were taken using questionnaires and interviews. The results showed that the students' music tastes, habits of listening to English music, and fatigue factors influenced their enjoyment of learning English by using rap music. However, students often exposed to English songs, considered it necessary to apply English teaching using rap music media. The student felt motivated to learn the pronunciation of rap music, which they judged too fast. The positive thing obtained from teaching using rap music was that most of the students would relax without feeling tense when they were learning if it compared to the conventional method.
\end{abstract}

Keywords: rap music, student, perception, English learning

\section{INTRODUCTION}

The use of music in teaching English, according to several studies, can have a positive impact on learners' cognitive and affective. Several studies have shown that music has a role in the development of vocabulary acquisition, pronunciation, grammar, and increasing students' motivation [1]-[6]. In cognitive development, music plays a role in improving students' learning outcomes. Meanwhile, the role of music in affective development is to create a comfortable atmosphere.

The application of music in teaching language is famous with a method called suggestopedia. This method was conceived by Lazanov [7], which stated that this method used a teaching technique such as music, drama, or games. Through this technique, the classroom atmosphere is relaxed, and this method requires that teachers do not provide much hard homework. The material provided by using the suggestopedia method is given in a fun way so that it can be understood spontaneously. Thus, teaching with rap music media applied in this study was the suggestopedia method. Through this method, the classroom atmosphere should be relaxed, enjoyable, and can facilitate young learners to understand the material.

The variety of music used in class depends on the purpose of teaching [8]. If teaching aims to make learners actively moving, the teacher is advised to use a type of music that is rhythmic rather quickly. Therefore, there needs to be a consideration in choosing the type of music used. Referring to the consideration of learner characteristics and learning objectives, researchers determined the type of rap music as a teaching medium to attract the attention of learners at the elementary school level and make them focus. According to Mora [4], music rhythm and lyrics intonation make children interested in learning and make them focus.

There are various time options applied to involve music in teaching activities [8]. Music can be applied before learning activities begin, that is before the teacher gives the material. It also could be used to accompany learners while moving (by using fast tempo music) as well as while learning is busy doing assignments, either individually or in groups (use music that makes it easy for them to do the task) as background. Besides, the teacher could use it when the learning activities end.

Compared to the application of rap music as a teaching medium in America, its application in Indonesia is not yet quite well-known. Rap music in America has started to be used in learning since the 1980s, while in Indonesia, this music was popular in the community in the 1990s. However, the government prohibited the existence of this music because it was not following the culture of the Indonesian people and could damage the morale of young people [9]. Nowadays, the government has removed the ban, and even rap music has begun to apply in the sphere of education. For example, rap music is taught in schools to develop students' singing or dancing talents. Based on sources from several schools, there are about 16 schools that apply this music in hip hop extracurricular classes.

The subjects of this research were elementary school students in grades 4 and 5, with an average age of 9-11 years. Learners at this age, according to Harmer [10] have cognitive difficulties in learning abstract concepts of language, have a limited concentration range, and are easily bored. According to Piaget, it turned out that the age range showed different characteristics [11]. It was like the statement of Cephe and Keskil [12] and Harmer [10] that 
children in the age range 10-11 years were interested in games, songs, and puzzles. Different to the children aged 10-11 years, the children between 12 and 13 years are involved in discussion activities, questions, and answers, as well as matching exercises. Each of them has different experiences both from the school environment and from the social environment [10], [13]. Their experience can influence their interest in learning and learning outcomes. By still considering the characteristics of children according to various experts, the researchers used rap music media to analyze students' responses to learning using music media, especially rap. This research would see whether rap can minimize the difficulties and students' boredom in learning English. Besides, this study aimed to broaden the reach of learning research with rap music suggested by Hill and Petchauer [14]

\section{METHOD}

The population of this study was 36 elementary school students, and the sample of this study was 18 grade 4 elementary school students who obtained English language teaching using rap music in the extracurricular class. The data used in this study were researchers' notes, questionnaire results, and interviews. The procedure for administering pre-research questionnaires was carried out before the treatment given, and the post-research questionnaire was given together after the research end. Meanwhile, a semi-structured interview carried after completing the other data collection procedures. The procedure of taking researchers' notes was only done in the experimental group to complete the questionnaire and the data interview. The procedure of data collection by using the researcher notes was carried out during the teaching process only in observing everything that stands out in the classroom.

The questionnaire used in this study was a questionnaire adapted from Bonilla Research [7]. The adaptation made by changing several things, i.e. : (1) translating the language from English to Indonesian as a language abilities of the research subject, (2) eliminating some questions, (3) adding questions related to the subject's perception of rap music. Both pre- and post-research used questionnaires. The former investigated students' perceptions of music and English songs used in the classroom. It consisted of six questions with opened answers and two questions with closed-answers. While the Post-research questionnaire included the students' perceptions of the application of rap music media in teaching English, this questionnaire contained three open questions and six closed questions.

\section{RESULTS AND DISCUSSION}

Based on the curriculum designed by Segal[15], the researcher chose rap music with lyrical content that had informal poetry and registers. Researchers adjust the lyric content with teaching material. The Rap music used in this study was from Youtube, such as Flocabulary and Fluency MC Youtube Channel. They were Hello, What is Pronoun, Don't You Know Rap Song, How Bored I am, Past Simple Rap Song, and Past Tense Verbs Rap. The rap integrated as an ice breaker activity at the beginning, and after the learner was familiar with the material.

\subsection{Analysis of Questionnaire for Pre- Research}

Table 1 . shows that there are $84 \%$ of students said they liked music, $4 \%$ of students said they quite liked music, and $12 \%$ of students said they did not like music. The statements in this questionnaire also explained their concern for learning English using music. There are $96 \%$ of students not accustomed to teaching English by using music, while 4\% admitted to being accustomed since they take English courses outside of school.

Table 1 Students' favourite music

\begin{tabular}{|lccc|}
\hline \multicolumn{1}{|c}{ Students' statement } & Yes (\%) & Moderate (\%) & No (\%) \\
\hline Students like music & 84 & 4 & 12 \\
The teacher applies music in the learning process & 4 & - & 96 \\
Students know about music & 8 & - & 92 \\
\hline
\end{tabular}

They explained various reasons why they love music. They stated that music could make them happy, could eliminate anger, and cheer them up. The reason why students love music supported the theory of Sousa [8], which stated that music plays a role in shaping one's mood. Some of the reasons presented by the learners showed the positive influence of music in themselves personally; i.e., they could turn into happy, sad, or feel other emotions because of music.

Furthermore, $4 \%$ of students said that they did not quite like music because some music genres were not fun for them. The student's statement could imply that not all music genres were suitable and preferred so that not all of them were suitable for teaching media. The researcher I was referring to the opinions of these learners, teachers who would apply music, need to consider the music genre by understanding the students' favourite music. Meanwhile, $12 \%$ of students said they did not like music because they were accustomed to listening to music both at home and at school.

The majority of students answered that they did not know rap music while only a few students, as many as $8 \%$, stated that they knew rap music. Those who answered knowing rap music explained that rap music was a type of rap music with a quick tone and made them excited. 
Table 2 Students' habits and preferences to listen to English music

\begin{tabular}{|lccccc|}
\hline \multicolumn{1}{|c}{ Question } & $\mathbf{1}$ & $\mathbf{2}$ & $\mathbf{3}$ & $\mathbf{4}$ & $\mathbf{5}$ \\
\hline $\begin{array}{l}\text { I like to listen to English song } \\
\text { while doing homework }\end{array}$ & 8 & 16 & 20 & 24 & 32 \\
$\begin{array}{l}\text { I like to listen to English } \\
\text { music/song when relaxing }\end{array}$ & 8 & 20 & 16 & 32 & 24 \\
\hline
\end{tabular}

Based on the table 2, the total number of learners strongly agree and disagree with the statement of having a habit of listening to English songs while doing homework was 56\%. Almost the same as a result, students who expressed uncertainly, disagree, and strongly disagree with the statement were $44 \%$. This figure showed that although in the first statement, the majority of students said they liked music, their comments in the next questionnaire showed that there were students who said they liked music. However, they did not have the habit of listening to English music. Among learners who claimed to like music, there were learners who rarely or did not have the habit of listening to English music. Thus, listening to English music was not necessarily their habit.

The second statement implied the same thing as the previous statement. The learners who stated agree and strongly agreed were $56 \%$, and those who expressed uncertainly, disagree, and strongly disagree to listen to music while relaxing was $44 \%$. When it confirmed, indeed, many of them said they liked listening to music but not English music. Most of them liked to listen to Indonesian music Indonesian when they had free time or while doing work.

\subsection{Post-Research Questionnaire Analysis}

To measure the extent to which students liked and wanted to apply rap music in their daily lives, researchers provided the questionnaire by using answer scales; a scale of 1 for answers strongly disagrees, 2 for answers disagrees, 3 for uncertain, 4 for agree, and 5 for strongly agrees. The table below showed the percentage of learners' perceptions of rap music media implementation in teaching English. As many as $72 \%$ of students thought rap music made them happy. Meanwhile, there were $24 \%$ of students stated that rap music made them comfortable enough, and $4 \%$ of students said unhappily.

The learner has felt no tension when teaching English using rap music. They stated as if they felt like they were not learning. It was in the researcher's notes, which showed the role of rap music in forming a tense and relaxed atmosphere in the classroom.

Meanwhile, the students also showed the advantages of rap song content. They explained that the song's content made it easier to understand the English material. They thanked to help that made them understood and memorized vocabulary. Although this research was not focused on vocabulary mastery, this learner's statement could strengthen the presentation of Kao and Oxford [5] about the decisive role of rap in enhancing children's vocabulary abilities.

Another exciting thing the learners explained in their questionnaire that they felt happy but also felt a little bored because the extracurricular activities begin too late at 14.3015.30. This condition also might cause the implementation of rap music media in the extracurricular class was not quite effectively applied when compared to teaching without using rap music media. Besides being tired, they also were bored to listen to the song played and material explanation. Both activities were less attractive to them. It reinforces the statement of Cameron [13] and Harmer [10] that children would get bored quickly when they encountered less attractive teaching activities.

There were $72 \%$ of students felt happy when singing the rap lyric while clapping. On the other hand, $8 \%$ of students were happy when they listened to songs without clapped. It implied that singing activities were more attractive to children's learners than listening to songs or music. The next question examined their opinion about the role of rap music media in teaching English. There were as many as 25\% felt that the rap could help them understood the English they have learned, while there are $75 \%$ who felt quite helped. The majority of them conveyed in their questionnaire that rap could help them memorized new vocabulary well. It was from the results of observational notes in the third week of the intervention process. Researchers suspected that the repetition of the lyrics in the same tone made them easy to memorize new words with rap lyrics. Although they found it helpful, the majority of them found it a little challenging to keep up with the fast tempo of rap.

Table 3 The Result of Post-research Questionnaire

\begin{tabular}{|lccccc|}
\hline \multicolumn{1}{|c}{ Question } & $\mathbf{1}$ & $\mathbf{2}$ & $\mathbf{3}$ & $\mathbf{4}$ & $\mathbf{5}$ \\
\hline I am happy that rap music is used in teaching English & - & 8 & 36 & 24 & 32 \\
I would instead learn English without rap music than with it & 12 & 20 & 52 & 12 & 4 \\
I like listening to rap music while doing homework & 4 & 4 & 52 & 16 & 24 \\
I like listening to rap music when relaxing & 8 & - & 44 & 24 & 24 \\
Rap music can help me understand English lessons & - & - & 32 & 24 & 44 \\
\hline
\end{tabular}

Table 3 showed that students had a reasonably positive response to teaching rap music media. It indicated by the difference between the number of responses that stated strongly agree and agree was $56 \%$, and $32 \%$ were uncertain. There was a difference in the percentage that looked similar to two answers, about $18 \%$, plus there were still students who said they disagreed with the use of rap music media in the classroom. The second statement showed there were $32 \%$ of students stated strongly agree and agree, and there were $52 \%$ of students expressed doubt about the use of rap music media in the classroom. Meanwhile, there were still $16 \%$ of students who preferred traditional teaching methods than teaching using rap music media. 
When asked to state their daily habits of listening to rap music while doing homework or relaxing, $44 \%$ stated strongly agree to listen to rap music while doing homework actively, and $52 \%$ stated strongly agree and agree to listen to rap music when relaxing actively. Meanwhile, there were still many who expressed doubt; $52 \%$ of students stated that they were still hesitant to use rap music in their daily activities, and $44 \%$ expressed hesitation in listening to rap music while relaxing actively. Meanwhile, there are still 4\% and $8 \%$ of students who responded not to listen to rap music either when doing homework or when relaxing. Their response could indirectly show that they had less interest in rap music even though they were familiar with rap music. Even so, the majority of learners strongly agree and agree that rap music applied in teaching helps them understand English material. $68 \%$ of students stated strongly agree and agree with the positive influence of rap music in their understanding, while there are still $32 \%$ of students who expressed doubts about the benefits of rap music in understanding the material.

Based on the researcher's analysis, the students had a lack of responses to teaching using rap music media. Several factors could influence, such as socio-cultural conditions and the learner's habit. The socio-cultural conditions in Indonesia showed that the learners unfamiliar with rap music. As in the opinion of Engh [16] that teaching should consider sociological or socio-cultural factors of society in exposing music media in teaching. Therefore, the researcher believed that the learners' habits of certain types of music were important to consider. They stated that music with a slow tempo was better than music with a fast tempo like rap (Interview L, T, Dz, Fe, Fh, 29 November 2017). Therefore, although they felt more comfortable using rap music media, the majority of them suggested that rap music should not need too often used. Thus, it should be in combination with other learning media, such as music and games inside the group (Interview L, T, Dz, Fe, Fh, 29 November 2017). Their presentation in this interview could be used as a reflection for teachers to combine rap music media with other media.

The results of other qualitative data analysis were $12 \%$ of learners did not like music at all, so teaching English by using music did not affect increasing their learning value. One of the learners who experienced this was H. He was not interested in teaching by using music because he did not like music. He repeatedly stated, both in the questionnaire and in the interview that he did not like music, so it was better to use teaching as usual. Therefore, teaching English by using music for him might not have a good effect. It is quite surprising because children who do not like music like $\mathrm{H}$ were rarely found. Abhat [17] stated that there are $3-5 \%$ of people in the world having musical anhedonia, which was the inability to feel the joy of music. Abhat's statement [17] referred to the research of Mas-Herrero et al., which resulted in the finding that some people claimed to hate music, not interested in responding to music.

In conclusion, since the teacher usually were taught by using conventional strategies, it became difficult for them to adapt to the new teaching. Because they were less exposed and unfamiliar with rap music, this caused them to feel quite tricky. Third, it was necessary to use other media combined with teaching using rap music media. Fourth, the results of the application of the media became less effective for learners who might have musical anhedonia. In particular, the results of observational notes indicated that the implementation of teaching by using music was less effectively applied in extracurricular classes was likely caused by their fatigue.

\section{CONCLUSION}

Learners' perception of the application of rap music media in teaching English shows quite positive results. As many as $56 \%$ of students feel happy to get teaching with rap music while there are $40 \%$ of students who feel quite happy, and there are still $8 \%$ of students who feel unhappy. From the results of this questionnaire, it turns out students' perceptions of rap music are still related to their musical tastes. Those who do not want to apply to listen to Englishlanguage rap music in their daily lives admit that they do not like rap genre music, and some argue because they do not like music at all. Elementary school learners will experience a higher level of difficulty when singing rap that has a fast tempo. Besides, they are very rarely or never exposed to English music in their daily lives. Nevertheless, the advantage of using rap music in the classroom is that rap can form a comfortable classroom environment for students.

\section{REFERENCES}

[1] J. K. Swaminathan, S., \& Gopinath, 'Music Training and Second-Language English Comprehension and Vocabulary Skills in Indian Children', Psychol Stud, vol. 58, no. 2, pp. 164-170, 2013.

[2] M. Moradi, M., \& Zamanian, 'On Effect of Soft Music on Learning English Language Vocabulary', Theory Pract. Lang. Stud., vol. 4, no. 2, pp. 341-348, 2014.

[3] A. S. Kara, Z. E., \& Aksel, 'The Effectiveness of Music in Grammar Teaching on Motivation and Success of the Students at Preparatory School at Uludag University', Soc. Behav. Sci., vol. 106, no. 2013, pp. 2739-2745, 2013.

[4] C. F. Mora, 'Foreign Language Acquisition and Melody Singing.', Foreign Lang. Acquis. Melody Sing., vol. 54, no. 2, pp. 146-152, 2000.

[5] R. L. Kao, T. a., \& Oxford, 'Learning Language through Music: A Strategy for Building Inspiration and Motivation.', System, vol. 43, no. April 2014, pp. 114 120, 2014.

[6] M. Mashayekh, M., \& Hashemi, 'The Impact/s of Music on Language Learner's Performance.', Procedia - Soc. Behav. Sci., vol. 30, no. 2011, pp. 2186-2190, 2011. 
[13] L. Cameron, Teaching Language to Young Learner. UK: Cambridge University, 2001.

Enhancing ESL Learners' Motivation through Music, Relaxation Technique, and Role Playing', 2015.

[8] D. A. Saosa, How the Brain Learns, Fifth. USA: Corwin A Sage Company, 2011.

[9] M. Bodden, 'Rap in Indonesia Youth Music of 1990s: "Globalizations", "Outlaw Genres", and Social Protest', Asian Music, vol. 36, no. 2, pp. 1-26, 2005.

[10] J. Harmer, The Practice of English Language Teaching, Fourth. London: Pearson Longman, 2007.

[11] H. D. Brown, Principle of Language Learning, Fifth. White Plains: Pearson Education Inc, 2007.

[12] G. Keskil and P. T. Cephe, 'Learner variables in learning English', Mod. English Teach., vol. 10, no. 1, pp. 57-61, 2001.
[14] E. Hill, M.L., \& Petchauer, Expanding Hiphop Based Education Across the Curriculum. Columbia: Teachers Colege, 2013.

[15] B. Segal, 'Teaching English as a Second Language Through Rap Music: A Curriculum for Secondary School Students', University of Sanfransisco, 2014.

[16] D. Engh, 'Why Use Music in Language Learning? A Survey of Literature', English Lang. Teach., vol. 6, no. 2, pp. 113-127, 2013.

[17] D. Abhat, 'Inside the Heads of People Who Don't Like Music', 2017. 